\title{
Microendoscopy-guided percutaneous cordotomy for intractable pain: case series of 24 patients
}

\author{
Erich Talamoni Fonoff, MD, PhD, ${ }^{1}$ William Omar Contreras Lopez, MD, PhD, ${ }^{1,2}$ \\ Ywzhe Sifuentes Almeida de Oliveira, MD, ${ }^{1}$ and Manoel Jacobsen Teixeira, MD, PhD ${ }^{1}$
}

${ }^{1}$ Pain Center and Division of Functional Neurosurgery, Department of Neurology, School of Medicine, University of São Paulo, Brazil; and ${ }^{2}$ Department of Stereotactic and Functional Neurosurgery, University Medical Center, Freiburg, Germany

OBJECTIVE The aim of this study was to show that microendoscopic guidance using a double-channel technique could be safely applied during percutaneous cordotomy and provides clear real-time visualization of the spinal cord and surrounding structures during the entire procedure.

METHODS Twenty-four adult patients with intractable cancer pain were treated by microendoscopic-guided percutaneous radiofrequency (RF) cordotomy using the double-channel technique under local anesthesia. A percutaneous lateral puncture was performed initially under fluoroscopy guidance to localize the target. When the subarachnoid space was reached by the guiding cannula, the endoscope was inserted for visualization of the spinal cord and surrounding structures. After target visualization, a second needle was inserted to guide the RF electrode. Cordotomy was performed by a standard RF method.

RESULTS The microendoscopic double-channel approach provided real-time visualization of the target in $91 \%$ of the cases. The other $9 \%$ of procedures were performed by the single-channel technique. Significant analgesia was achieved in over $90 \%$ of the cases. Two patients had transient ataxia that lasted for a few weeks until total recovery.

CONCLUSIONS The use of percutaneous microendoscopic cordotomy with the double-channel technique is useful for specific manipulations of the spinal cord. It provides real-time visualization of the RF probe, thereby adding a degree of safety to the procedure.

http://thejns.org/doi/abs/10.3171/2014.12.JNS141616

KEY WORDS pain; endoscopy; spinal endoscopy; radiofrequency; minimally invasive neurosurgery; spinothalamic tract; cancer; percutaneous cordotomy; spinal cord; surgical technique

$\mathrm{C}$ ANCER is often associated with pain, which, if inadequately treated, can severely deteriorate quality of life. ${ }^{26}$ Although great progress has been made in the treatment of cancer pain, not all patients can be treated satisfactorily. ${ }^{10}$ In particular, neuropathic pain and incidental breakthrough pain, due to nerve compression or pathological bone fractures, can be notoriously difficult to control even using optimized opioid therapy. ${ }^{7}$ In general, pain treatment in these cases consists of a combination of analgesics and coanalgesics. Once this approach is deemed insufficient, continuous subcutaneous, intravenous, or spinal infusion techniques can be applied in addition. However, these therapies may fail in some patients, who then continue to be dissatisfied. In such situations, percutaneous cervical cordotomy (PCC) can be a valuable additional therapeutic option, especially when the pain is predominantly unilaterally localized. ${ }^{3}$ Although this procedure is presented less often in the current literature, a review published by Raslan et al. in $2011^{34}$ recommended cordotomy as an optional method to treat cancer pain.

ABBREVIATIONS PCC = percutaneous cervical cordotomy; RF = radiofrequency; $\mathrm{STT}=$ spinothalamic tract; VAS = visual analog scale.

SUBMITTED July 14, 2014. ACCEPTED December 18, 2014.

INCLUDE WHEN CITING Published online July 31, 2015; DOI: 10.3171/2014.12.JNS141616.

DISCLOSURE The authors would like to acknowledge the support of Fundação de Amparo a Pesquisa do Estado de São Paulo (FAPESP) grant \#2011/08529-5 and Ministério da Ciência e Tecnologia/Conselho Nacional de Pesquisa (MCT/CNPq) grant \#482365/2010-2. 
In the last decade, our group has been dedicated to the development of endoscopic procedures for the intrathecal space $^{12}$ by means of either percutaneous cordotomy ${ }^{11}$ or trigeminal nucleotractotomy. ${ }^{45}$ In this study, we propose a safer approach for these procedures. Although the first procedures allowed visualization of the spinal cord and targeting guidance by anatomical landmarks, the puncture of the spinal cord itself was performed blindly because of the need to withdraw the microendoscopic optics in order to insert the radiofrequency (RF) electrode into the single work channel. ${ }^{11}$ The procedure described herein allows real-time direct visualization of both the spinal cord and the probe during the whole procedure. This improvement apparently adds more accuracy and safety to the original procedure described by our group previously. ${ }^{11}$ We describe this technique and its effectiveness in 24 patients.

\section{Methods \\ Inclusion Criteria}

This was a prospective study that included 24 adult patients with predominantly unilateral intractable pain related to advanced cancer in the thorax and lower body, which worsened in the upright or sitting positions (mechanical/incidental pain). All patients were treated at the Pain Center and Division of Functional Neurosurgery at the Hospital das Clinicas of the University of São Paulo between January 2009 and December 2012. Patients were followed up for at least 1 year, but some of the patients died of cancer before 1 year. Pain ratings were obtained according to the visual analog scale (VAS) on the day before the procedure, the 1st operative day, and during the postoperative follow-up at $1,3,6$, and 12 months.

\section{Surgical Technique \\ Microendoscopy-Guided Percutaneous Double-Channel Technique for RF Cordotomy}

The procedures were carried out under local anesthesia and light sedation when needed. In the case of using any sedation at the beginning of the operation, it was carefully titrated such that the patient was sufficiently responsive and cooperative for the subsequent sensory testing during the intraoperative electrostimulation mapping.

Patients were placed in the supine position, with the head secured in a Rosomoff head holder with slight anterior flexion of the neck. Initially, fluoroscopy was positioned to guide the puncture on the skin and deep muscle tissue in the upper lateral cervical region (approximately $1 \mathrm{~cm}$ caudal and dorsal to the mastoid process) for local anesthesia. When appropriate, the anesthesiologist administered the continuous intravenous infusion of $2-4 \mu \mathrm{g} / \mathrm{kg} /$ min propofol or $0.1-0.4 \mu \mathrm{g} / \mathrm{kg} / \mathrm{hr}$ dexmedetomidine infusion. ${ }^{38}$ A nasal catheter delivered 1-2 L/min oxygen. We also found that intravenous droperidol administered at a low dosage was very useful (1.25-mg intravenous bolus). Patient monitoring consisted of electrocardiography, pulse oximetry, and noninvasive blood pressure monitoring. Patients were carefully observed to ensure that they were still able to communicate verbally during the whole procedure.

Under fluoroscopic visualization, a 17-gauge cannula was inserted into the lateral aspect of upper cervical area, perpendicular to the skin and toward the spinal canal in the C1-2 interspace (Video 1).

VIDEO 1. Lateral puncture of the spinal canal in the C1-2 interspace was performed using fluoroscopy guidance. As soon as the CSF was reached by the guide cannula (17-gauge needle), the endoscope was inserted for visualization of the spinal cord and surrounding structures. Endoscopic visualization provided clear identification of the pial surface of the spinal cord, arachnoid membrane, dentate ligament, dorsal and ventral root entry zone, and blood vessels. A second cannula was introduced in the same way in order to guide the electrode insertion under direct visualization. The target for electrode insertion into the spinal cord was determined to be the midpoint between the dentate ligament and ventral root entry zone. Cordotomy was performed by the standard RF method after refining the target with intraoperative stimulation. Copyright Erich Talamoni Fonoff. Published with permission. Click here to view with Media Player. Click here to view with Quicktime.

Once the CSF was reached, fluoroscopy was no longer employed (Fig. 1). Once the dura mater was punctured, the cannula became rather fixed by the skin, cervical muscles, and dura itself, allowing a few millimeters of narrow mobility. Through the cannula, a $0.9-\mathrm{mm}$-thick microendoscope (Myelotec, Inc.) was inserted for direct viewing of the spinal canal. This device renders a $70^{\circ}$ field of view (FOV) with $40 \times$ magnification at the $0^{\circ}$ angle of view, which provides a clear image through the CSF (Fig. 2). Although the resolution of the microendoscope was lower than the endoscopes used in intraventricular procedures, it still provided clear standard images. This procedure allowed visual identification of the dentate ligament, lateral aspects of the spinal cord, nerve rootlets, trabeculae of the arachnoid membrane, and blood vessels. After identification of the important landmarks, a second cannula was inserted next to the first one in order to reach the same space. The second cannula was used for the RF electrode under direct spinal cord visualization by endoscopy (Fig. 3).

The spinothalamic tract (STT) is located in the spinal cord, topographically just anterior to the dentate ligament. The target for electrode insertion into the spinal cord was determined to be in the midpoint between the dentate ligament and ventral root entry zone. The exact spinal target was finely determined by electrostimulation mapping. The patient could clearly identify the sensation of the stimulus on the region affected by the pain, contralateral to the puncture side. A coated, fine, thermocouple RF electrode was used to map the exact location of the STT within the spinal cord by controlled electrical stimulation. Low-frequency stimulation $(2-5 \mathrm{~Hz})$ was used to evoke motor contraction, in case the electrode was misallocated posteriorly closer to the pyramidal tract. This fiber bundle lies just dorsal to the dentate ligament, $2-3 \mathrm{~mm}$ from the STT itself. Controlled electrical stimulation at a higher frequency $(50-75 \mathrm{~Hz}$ at $0.1-0.5 \mathrm{~mA})$ evokes either a tingling or a thermal sensation (either warm or cold) in the corresponding contralateral side of the body when the tip of the electrode stimulates the STT directly. After meticulous assessment of the correct position of the electrode tip by repeated stimulation, restricted thermal ablation of the STT was performed by application of the RF, resulting in a tip temperature of $75^{\circ} \mathrm{C}$ for 60 seconds..$^{11}$ Frequently, more than 1 lesion may be needed to reach the desired level of analgesia. The decision is often made based on the 


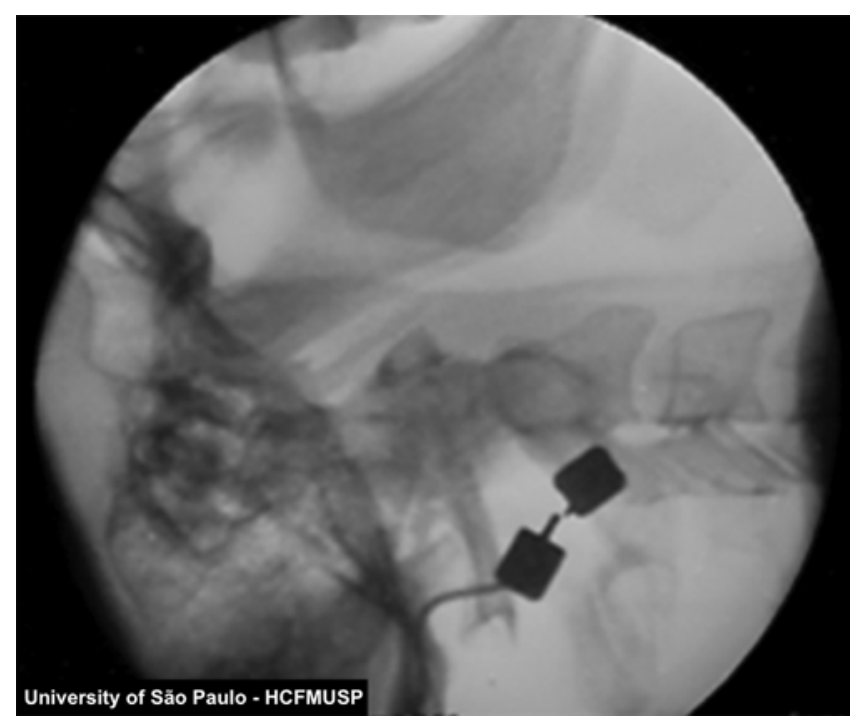

FIG. 1. Guide cannulas introduced into the C1-2 interspace, with the tips 1-2 $\mathrm{mm}$ apart at the same site.

results of the intraoperative neurological examination; if the pinprick sensation in the desired territory is not abolished, the surgeon may decide to reapply the RF lesion to the same target or change the RF electrode position to a new lesion.

The STT is a somatotopically organized structure, so this feature can be rightly used to refine the target for ablation. Ventromedial fibers innervate the contralateral upper limb and chest region, while the dorsolateral fibers cover the contralateral inferior trunk, lumbar area, abdomen, lower limb, and sacral region. Depending on the region affected by pain, the target in the spinal cord can be carefully modified according to somatotopy within the tract. The surgeon can orient the RF probe either ventral or dorsally, or more medially or laterally if needed. Pinprick sensation is tested in the body after each ablation. Additional lesions may be applied according to the functional results of pinprick and thermal analgesia. Immediate and sustained pain relief is obtained right after the procedure. The technique is described extensively elsewhere.,11 The cannulas were withdrawn at the end of the procedure, and small adhesive bandages were applied over the puncture sites. The patients were permitted to stand up and walk the day after the procedure, and most were discharged from the hospital on the same day. If a patient was using high dosages of opioids, special attention was required to lower the opioid dosage in order to avoid withdrawal syndrome. In general, it is important to identify severe or moderate respiratory deficits prior to indication since pain can induce pathologically excessive use of the respiratory muscles. Respiratory failure can be a risk once the painful arousing stimuli are interrupted, and the remaining opioid medications can expose the patient to hypoventilation.

Patients were advised about the possibility of transient ataxia, which may frequently develop on the same side as the STT lesion. This is attributed to the partial spinocerebellar tract lesion. This tract is adjacent and more super-
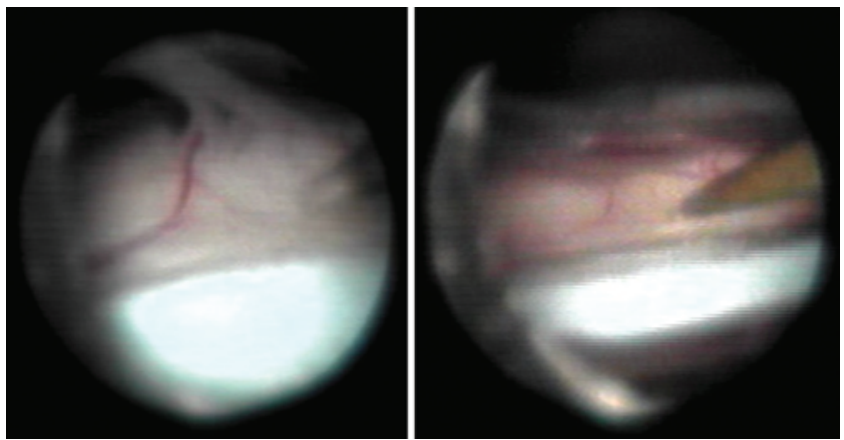

FIG. 2. Left: Microendoscopic view of the lateral aspects of the spinal cord, emergence of the ventral nerve roots (upper portion of the image), and the electrode tip (at right) pointing to the target and the dentate ligament (bright white structure at the bottom of the field of view). Right: The same view after spinal cord puncture. Figure is available in color online only.

ficially located to the STT within the spinal cord, so the RF lesion is likely to include it. Patients also had to be aware of the expected decrease in skin temperature and pain sensation, which may involve the entire half of the body below the neck. However, the sense of touch and proprioception remain intact. Effective cordotomy for unilateral pain may unmask pain on the opposite side, which is usually not clearly reported by the patient prior to the procedure. The expected side effects of the procedure, aside from mild headache and neck discomfort lasting 1 to 2 days, include Horner's syndrome on the side of the STT lesion that is probably related to the partial interruption of the ciliospinal tract. ${ }^{16}$

\section{Statistical Analysis}

We used 1-way ANOVA and Kruskal-Wallis repeated measures to analyze the results using Prism 6.0c (GraphPad Software, Inc.).

\section{Results}

The patient population in this study was $62 \%$ men and $38 \%$ women. Patients had pain related mostly to metastatic disease in $38 \%$ of cases, followed by lung and prostate cancer in $21 \%$ of cases, respectively; other etiologies included breast cancer in $12 \%$ and squamous cell carcinoma in $8 \%$ of patients (Table 1). Satisfactory pain control was obtained in all patients (Fig. 4). These results do not appear to differ from those of other authors. ${ }^{2,3,29}$ In the short term, pain control is usually excellent, but pain may recur due to disease progression to the contralateral side that is not covered by the procedure.

The proposed double-channel microendoscopic percutaneous cordotomy technique provided simultaneous visualization of the spinal cord target point and the RF probe in $91.7 \%$ of cases. In 2 cases, the single-channel technique permitted the completion of the procedure. Pain control was satisfactorily achieved after cordotomy, which is consistent with previous results. ${ }^{2,3,22}$ Short-term pain control is usually excellent, but pain may recur due to disease progression on the contralateral side that is not 


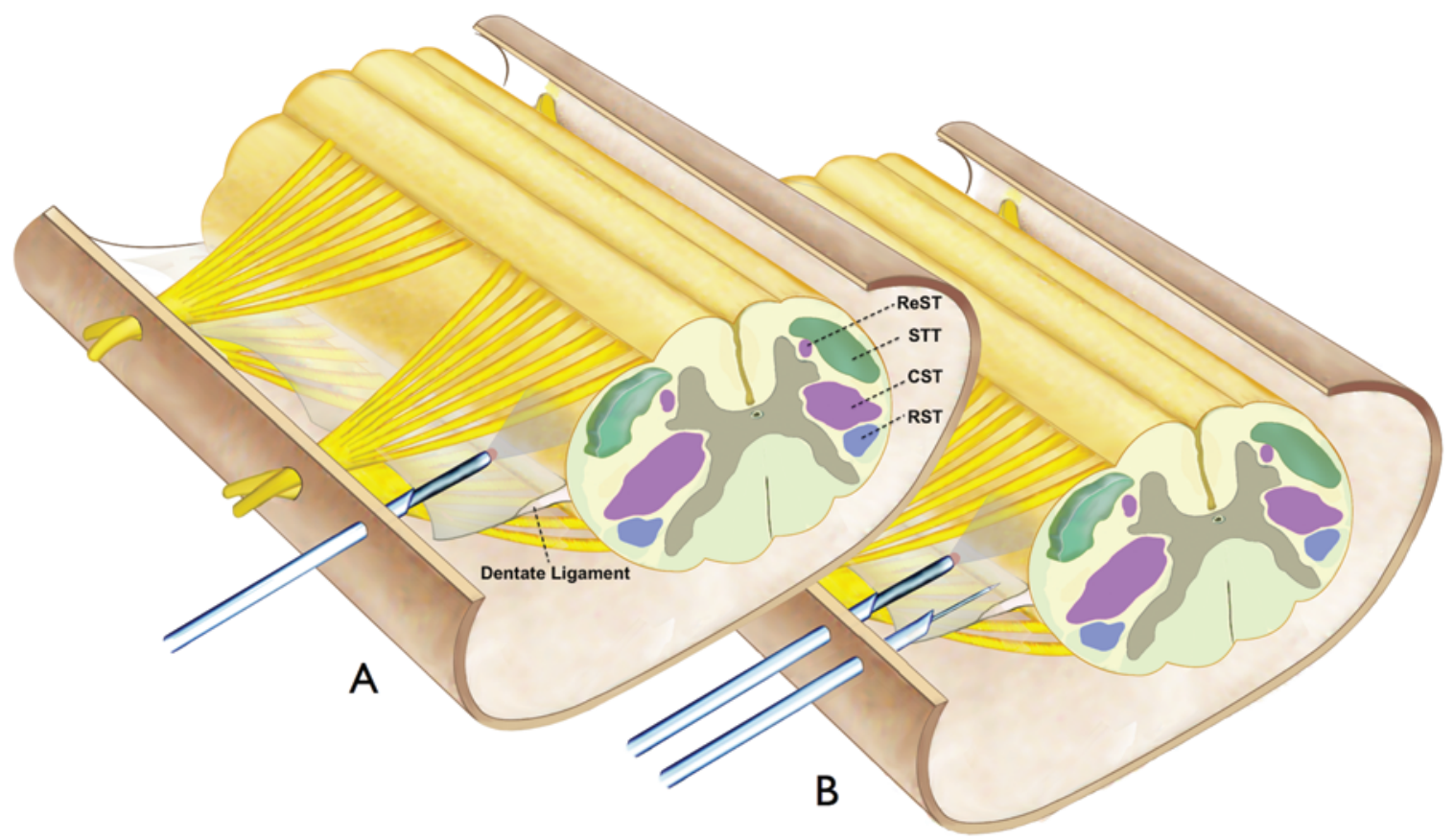

FIG. 3. Stepwise procedure for the microendoscopic cordotomy technique. Step 1: Insert the 17-gauge cannula perpendicular to the skin toward the spinal canal at the C1-2 interspace under fluoroscopic visualization. Step 2: Once the subarachnoid space is reached, the endoscope is introduced (A). Step 3: The second cannula is introduced in a parallel channel, also reaching the CSF space close to the first dural puncture (B). Step 4: Target identification followed by spinal cord puncture. Step 5: Stimulation and thermal RF lesion application, followed by intraoperative neurological examination (pinprick). CST = corticothalamic tract; ReST $=$ reticulospinal tract; RST = rubrospinal tract. Copyright Erich Talamoni Fonoff. Published with permission. Figure is available in color online only.

covered by the procedure. During the follow-up, the average pain scores tended to increase mainly due to neoplastic disease progression to the contralateral hemibody. Two patients presented with significant ataxia lasting for a few weeks until total recovery. There were no observed CSF leaks, permanent morbidity, or intraoperative/postoperative mortality in this series. Patients tolerated the procedure without difficulties and, at most, complained of mild headache during the immediate postoperative period.

\section{Discussion}

Percutaneous cervical cordotomy was introduced in 1963 by Mullan ${ }^{30}$ and modified by Rosomoff ${ }^{36}$ in 1965 as an evolved form of the classic open spinothalamic tractotomy, which was first performed in 1912 by Spiller and Martin $^{41}$ and later in 1932 by Foerster and Gagel for the treatment of intractable cancer pain. ${ }^{13}$

PCC is the thermocoagulation ablation of the STT, which routes through the anterolateral white matter column of the spinal cord. This was the most frequently performed procedure until the mid-1980s and considered the best alternative for the treatment of severe cancer pain. However, its popularity decreased considerably due to the widespread availability of oral, transdermal, and chronic spinal infusion opioid therapies. Although opioids are very effective drugs for pain, side effects may limit their use. ${ }^{39}$ Clinical situations, such as incidental breakthrough pain related to the bony or neoplastic plexus and nerve root in- vasion, respond poorly to both systemic and spinal opioid therapies. Patients with these conditions may benefit from cordotomy. ${ }^{27}$ When anterolateral cordotomy is performed adequately, the patient completely loses all forms of pain and temperature sensations in the intended area below the level of the lesion on the contralateral side of the body, including breakthrough pain. Cordotomy is frequently indicated for intractable pain in the lower limbs and thoracic and dorsal levels; however, according to the somatotopy of the STT, this procedure can also effectively induce analgesia in the brachial segments. This loss of pain and temperature sensation is usually sustained for several years in the majority of patients. ${ }^{46}$ However, in some patients, pain can recur within several months. In most cases, the apparent recurrence of pain after successful cordotomy is related either to the progression of the malignant disease or, in a few cases, new forms of central deafferentation pain. ${ }^{4}$ In rare cases, pain may occur on the contralateral side in a mirror location from the original pain area, which may be referred pain due to changes in the central circuits ${ }^{31}$ following anterolateral cordotomy. Unilateral cordotomy can eliminate the general nociceptive somatic pain sensation, pain from pressure on bones and soft cutaneous tissue, and even deep pain. Bilateral anterolateral cordotomy may completely eliminate pain due to testicular compression and renal pelvis pain; however, it can also abolish erections and ejaculation in males, as well as orgasm and libidinous sensations in males and females. ${ }^{46}$

Continuous spinal infusion techniques have caused a 
TABLE 1. Demographic data and patient outcomes

\begin{tabular}{|c|c|c|c|c|c|c|c|}
\hline \multirow[b]{2}{*}{$\begin{array}{l}\text { Case } \\
\text { No. }\end{array}$} & \multirow[b]{2}{*}{ Sex } & \multirow[b]{2}{*}{$\begin{array}{l}\text { Age } \\
\text { (yrs) }\end{array}$} & \multirow[b]{2}{*}{ Etiology } & \multirow[b]{2}{*}{ Pain Location } & \multicolumn{2}{|c|}{ Pain Control (\%) } & \multirow[b]{2}{*}{ Follow-Up } \\
\hline & & & & & Immediate & $\begin{array}{l}\text { At Last } \\
\text { Follow-Up }\end{array}$ & \\
\hline 1 & M & 55 & Lung carcinoma & Right hemithorax & 100 & 60 & $12 \mathrm{mos}$ \\
\hline 2 & M & 56 & Lung carcinoma & Left hemithorax and lumbar region & 100 & 44 & $3 \mathrm{mos}$ \\
\hline 3 & M & 47 & Carcinoma of the prostate & Bilateral lumbar region and left lower limb & 77 & 77 & $12 \mathrm{mos}$ \\
\hline 4 & M & 43 & $\begin{array}{l}\text { Multiple squamous cell carcinoma and bra- } \\
\text { chial plexus invasion }\end{array}$ & Left hemithorax and left arm and shoulder & 100 & 22 & $12 \mathrm{mos}$ \\
\hline 5 & $\mathrm{~F}$ & 58 & Breast carcinoma with lung metastasis & Left hemithorax & 70 & 30 & $6 \mathrm{mos}$ \\
\hline 6 & $\mathrm{~F}$ & 51 & Lung cancer & Right upper limb and right hemithorax & 100 & 37 & $12 \mathrm{mos}$ \\
\hline 7 & M & 62 & $\begin{array}{l}\text { Lung cancer with widespread bone meta- } \\
\text { stases }\end{array}$ & $\begin{array}{l}\text { Right hemithorax, abdomen, and bilateral lum- } \\
\text { bar region }\end{array}$ & 75 & 62 & $12 \mathrm{mos}$ \\
\hline 8 & $\mathrm{~F}$ & 84 & $\begin{array}{l}\text { Metastases in the left lumbosacral plexus. } \\
\text { Primary tumor was not identified }\end{array}$ & Left hip and lower limb & 70 & 20 & $12 \mathrm{mos}$ \\
\hline 9 & M & 48 & $\begin{array}{l}\text { Carcinoma of the prostate. Prior cordotomy } \\
\text { performed } 9 \text { mos before on the right } \\
\text { side }\end{array}$ & Left hip and lower limb & 100 & 100 & $6 \mathrm{mos}$ \\
\hline 10 & $\mathrm{~F}$ & 46 & $\begin{array}{l}\text { Carcinoma of the cervix with left hip for } \\
\text { bone metastases }\end{array}$ & Left hip & 90 & 60 & $12 \mathrm{mos}$ \\
\hline 11 & M & 47 & L-4 metastases of prostate carcinoma & Left lower limb & 100 & 100 & $6 \mathrm{mos}$ \\
\hline 12 & M & 62 & Lung cancer with metastases in left hip & Left hip & 100 & 55 & $12 \mathrm{mos}$ \\
\hline 13 & M & 53 & $\begin{array}{l}\text { Pain in the left lumbosacral plexus metas- } \\
\text { tases from bladder carcinoma }\end{array}$ & Left lower limb & 87 & 12 & $12 \mathrm{mos}$ \\
\hline 14 & $\mathrm{~F}$ & 47 & $\begin{array}{l}\text { Carcinoma of the cervix with lung and bone } \\
\text { metastases }\end{array}$ & Right hemithorax & 75 & 50 & $12 \mathrm{mos}$ \\
\hline 15 & M & 55 & Lung carcinoma & Right hemithorax & 100 & 77 & $6 \mathrm{mos}$ \\
\hline 16 & M & 56 & Lung carcinoma & Right hemithorax & 75 & 62 & $12 \mathrm{mos}$ \\
\hline 17 & $\mathrm{~F}$ & 58 & Lung carcinoma & Right hemithorax & 100 & 80 & $3 \mathrm{mos}$ \\
\hline 18 & $\mathrm{~F}$ & 63 & Breast cancer & Right hemithorax and upper limb & 85 & 42 & $6 \mathrm{mos}$ \\
\hline 19 & M & 52 & Prostate carcinoma & Right lower limb & 66 & 11 & $12 \mathrm{mos}$ \\
\hline 20 & M & 47 & Carcinoma of the prostate & Left lower limb & 80 & 40 & $3 \mathrm{mos}$ \\
\hline 21 & M & 67 & Carcinoma of the prostate & Left lower limb & 88 & 33 & $12 \mathrm{mos}$ \\
\hline 22 & M & 59 & $\begin{array}{l}\text { Peritoneal carcinomatosis and lumbosacral } \\
\text { plexus limb }\end{array}$ & Abdomen and left lower limb & 100 & 100 & $6 \mathrm{mos}$ \\
\hline 23 & $\mathrm{~F}$ & 43 & Multiple squamous cell carcinoma & Left hemithorax and upper lumbar region & 77 & 55 & $6 \mathrm{mos}$ \\
\hline 24 & $\mathrm{~F}$ & 63 & Breast cancer & Left hemithorax & 100 & 100 & $12 \mathrm{mos}$ \\
\hline
\end{tabular}

further decline in a number of patients treated with cordotomy. However, the last 2 decades of results obtained at our institution with terminally ill cancer patients suffering from intractable unilateral pain and full access to anticancer therapies and current analgesic measures has shown us the benefits of cordotomy for certain patient populations.

In the $1960 \mathrm{~s}$, the cordotomy was performed using radiographic control (films) with air injected into the outline of the anterior border of the spinal cord. ${ }^{4}$ These films were replaced by myelography under fluoroscopy that used oily contrast media. However, these contrast media can no longer be used for conventional diagnostic myelography because they are known to cause adhesive arachnoiditis, ${ }^{25}$ which is an inflammatory reaction of the pia mater and arachnoid membranes. Adhesive arachnoiditis may result in a progressive fibrotic process, with myelopathy and syrinx formation. Much progress has been achieved in computed tomography-guided percutaneous cordotomy, demonstrating good results, and the use of safer contrast media. 5,15,24,33 Microendoscopy-guided procedures may be considered an evolved form of cordotomy. The present technique provides a clear detailed visualization of the spinal cord by avoiding vascular injuries and permitting the use of anatomical landmarks to guide target localization. In our experience, this technique significantly reduces the need for fluoroscopy and eliminates the need for contrast medium. ${ }^{11,12}$ We consider this approach a refinement of the first described technique, which used only 1 channel for the endoscope and RF probe. However, it is perfectly possible to perform a safe and contrast-free procedure using the single-channel technique. ${ }^{11}$

Immediately satisfactory pain relief was consistent- 


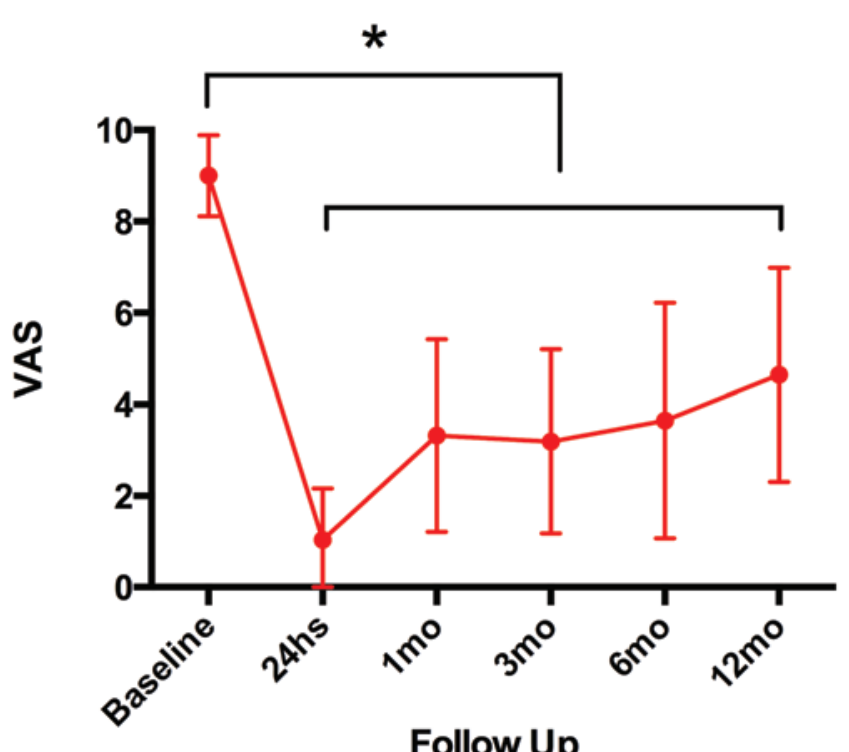

FIG. 4. Average VAS pain scores. The graph shows significant improvement of pain immediately after the procedure and at the latest follow-up. Determined using 1-way ANOVA and Kruskal-Wallis repeated measures $\left({ }^{*} p<0.0001\right)$. Figure is available in color online only.

ly achieved in all previously published series. Tasker and Franklin ${ }^{42}$ reported immediate pain relief in $94.4 \%$, Raslan $^{32}$ in 98\%, Kanpolat and Ugur in $92.5 \%,{ }^{24}$ and Rosomoff and $\mathrm{Papo}^{37}$ in $90 \%$ of patients. Moreover, $84 \%$ of patients demonstrated sustained improvement at the last follow-up in the Tasker series; $80 \%$ at 6 months in the Raslan series; and $84 \%, 61 \%, 43 \%$, and $37 \%$ at 3 months and 1, 5, and 5-10 years, respectively, in the Rosomoff series. The longest follow-up period was reported by Collins and Taren, ${ }^{8}$ who reported a 41-year follow-up of PCC for noncancer pain and achieved 35 years of complete analgesia.

Although cordotomy is the ablative procedure for controlling cancer pain with the highest number of reported patients, other procedures such as cingulotomy, ganglionectomy, mesencephalotomy, myelotomy, neuronotomy, neurectomy, rhizotomy, sympathectomy, thalamotomy, and tractotomy ${ }^{31}$ have been reported with excellent pain relief. Forty-seven papers, which include 3601 patients, have been published, but only 1 prospective trial by Raslan and Cetas $^{34}$ reports significant improvement in all outcome measurements: VAS, Karnofsky score, activities of daily living, and total sleeping hours. Still, clinical evidence relies on conventional Class III studies. Despite not having a Class I report, the vast majority of studies reported excellent pain relief. However, we think that cordotomy may be safer as an alternative procedure for cancer pain treatment. The best candidates for cordotomy are patients with unilateral somatic cancer pain and compression of the plexus, roots, or nerves with incidental breakthrough pain. ${ }^{3,4}$ Unilateral upper body pain (secondary to lung carcinoma, mesothelioma, or Pancoast tumors) and bilateral somatic intractable pain in the lower body and extremities can be controlled by selective cordotomy. ${ }^{21,23}$ Percutaneous cordotomy is highly effective in controlling local intractable pain due to malig- nancy. After the procedure, most patients do not need to contact the medical staff or even go to the hospital after ablation. With cordotomy, pain patients can return to their daily activities and eventually to work.

In cervical cordotomy, respiratory dysfunction is a rare complication. ${ }^{6,17,35}$ The risk is higher in patients with preexisting functional respiratory disorders. Cordotomy is contraindicated in patients with severe pulmonary dysfunction, those who are unable to stay in the supine position for 30 to 40 minutes, and those whose partial oxygen saturation is less than $70 \% .{ }^{28}$ Sleep-induced apnea is the most dangerous problem after bilateral cordotomy. ${ }^{14}$ Rosomoff ${ }^{35}$ reported respiratory problems in $4 \%$ and mortality due to sleep-induced apnea in $2 \%$ of their cases. The fibers that transmit pain from the upper trunk and upper limbs are located in the anterior and medial STT, which is adjacent to the ventrolateral reticulospinal tract. On the other hand, fibers from the lower trunk and limbs are located in the posterolateral aspects of the STT. ${ }^{5,15,24}$ For this reason, bilateral destruction of the pain fibers from the lower trunk and extremities at the upper cervical level seems to be safer than ablation of the fibers from the upper trunk and upper extremities. ${ }^{11,12}$ Kanpolat et al. advise bilateral cordotomy only for cases with bilateral abdominal, pelvic, or lower extremity pain..$^{19}$ However, bilateral cordotomy procedures have higher complication rates than unilateral procedures. ${ }^{1,5,18,29,35,40}$ The complications of conventional cordotomy include ipsilateral motor weakness (5\%-10\%), ataxia $(8 \%-34 \%)$, bladder dysfunction $(1.5 \%-17 \%)$, postcordotomy dysesthesia $(2 \%-5 \%)$, hypotension $(4 \%)$, and respiratory problems $(4 \%) \cdot{ }^{20}$ In this series, only 2 patients presented with transient ataxia that improved a few weeks after the procedure, and mild headache was present in $30 \%$ of patients after the procedure.

There are certain limitations and considerations to this approach. The endoscopic approach may eventually be limited by a narrow spinal canal or constitutional or epidural infiltration by neoplastic disease. This narrowing of the vertebral canal may restrict the distance between the spinal cord and the dura $(<1 \mathrm{~mm})$, thereby preventing the endoscopic view. Bilateral and midline pain, except when it is predominantly lateralized to 1 side, will require bilateral cordotomy. Mild headache and neck discomfort lasting 1 to 2 days usually occurs. Horner's syndrome ipsilateral to the spinal cord ablation confirms that the procedure was successful and is often not noticed by the patient. ${ }^{21,28,43}$ Urinary disturbances and muscles weakness may occur very seldom and are usually transient. Transient ataxia may develop on the side of lesion, and skin thermoanalgesia should be expected to occur.

\section{Conclusions}

Although PCC is very effective in controlling pain, this procedure was nearly abandoned, probably due to the low feasibility and apprehension regarding severe complications. The results of this case series suggest that the use of percutaneous microendoscopy with the double-channel technique can be useful for this particular manipulation of the spinal cord. To the best of our understanding, the described technique adds safety to the PCC procedure by pro- 
viding the target position based on the visualization of the individual anatomical landmarks and avoiding potential vascular damage, avoiding the use of intrathecal contrast injection, and reducing fluoroscopy exposure. Multicenter comparative studies are still needed to provide higher levels of evidence about the efficacy of this technique.

\section{References}

1. Amano K, Kawamura H, Tanikawa T, Kawabatake H, Iseki $\mathrm{H}$, Iwata $\mathrm{Y}$, et al: Bilateral versus unilateral percutaneous high cervical cordotomy as a surgical method of pain relief. Acta Neurochir Suppl (Wien) 52:143-145, 1991

2. Atkin N, Jackson KA, Danks RA: Bilateral open thoracic cordotomy for refractory cancer pain: a neglected technique? J Pain Symptom Manage 39:924-929, 2010

3. Bain E, Hugel H, Sharma M: Percutaneous cervical cordotomy for the management of pain from cancer: a prospective review of 45 cases. J Palliat Med 16:901-907, 2013

4. Batzdorf U, Weingarten SM: Percutaneous cordotomy. A simplified approach to the management of intractable pain. Calif Med 112:21-26, 1970

5. Bekar A, Kocaeli H, Abaş F, Bozkurt M: Bilateral high-level percutaneous cervical cordotomy in cancer pain due to lung cancer: a case report. Surg Neurol 67:504-507, 2007

6. Belmusto L, Brown E, Owens G: Clinical observations on respiratory and vasomotor disturbance as related to cervical cordotomies. J Neurosurg 20:225-232, 1963

7. Caraceni A, Bertetto O, Labianca R, Maltoni M, Mercadante $\mathrm{S}$, Varrassi G, et al: Episodic (breakthrough) pain prevalence in a population of cancer pain patients. Comparison of clinical diagnoses with the QUDEI-Italian questionnaire for intense episodic pain. J Pain Symptom Manage 43:833-841, 2012

8. Collins KL, Taren JA, Patil PG: Four-decade maintenance of analgesia with percutaneous cordotomy. Stereotact Funct Neurosurg 90:266-272, 2012

9. Crul BJP, Blok LM, van Egmond J, van Dongen RTM: The present role of percutaneous cervical cordotomy for the treatment of cancer pain. J Headache Pain 6:24-29, 2005

10. Deandrea S, Corli O, Consonni D, Villani W, Greco MT, Apolone G: Prevalence of breakthrough cancer pain: a systematic review and a pooled analysis of published literature. J Pain Symptom Manage 47:57-76, 2014

11. Fonoff ET, de Oliveira YSA, Lopez WOC, Alho EJL, Lara NA, Teixeira MJ: Endoscopic-guided percutaneous radiofrequency cordotomy. J Neurosurg 113:524-527, 2010

12. Fonoff ET, Lopez WOC, de Oliveira YSA, Lara NA, Teixeira MJ: Endoscopic approaches to the spinal cord. Acta Neurochir Suppl 108:75-84, 2011

13. Foerster O, Gagel O: Die Vorderseitenstrangdurchschneidung beim Menschen. Eine klinisch-patho-physiologisch-anatomische Studie. Ztschr ges Neurol Psychiat 138:1-92, 1932

14. Garber JE, Hassenbuch SJ: Neurosurgical operations on the spinal cord, in Loeser JD, Chapman R, Turk DC (eds): Bonica's Managements of Pain, ed 3. Philadelphia: Williams and Wilkins, 2001, pp 2023-2037

15. Gilbert JW, Wheeler GR, Mick GE, Herder SL: Computed tomography-guided percutaneous cordotomy. Neurosurgery 67:E521, 2010

16. Henriques FG, Leão IA: [Ciliospinal reflex in man.] Arq Neuropsiquiatr 34:258-265, 1976 (Portuguese)

17. Hitchcock E, Leece B: Somatotopic representation of the respiratory pathways in the cervical cord of man. J Neurosurg 27:320-329, 1967

18. Ischia S, Luzzani A, Ischia A, Maffezzoli G: Bilateral percu- taneous cervical cordotomy: immediate and long-term results in 36 patients with neoplastic disease. J Neurol Neurosurg Psychiatry 47:141-147, 1984

19. Kanpolat Y: Cordotomy for pain, in Winn HR (ed): Youman's Neurological Surgery, ed 5. Philadelphia: Saunders, 2004, Vol 3, pp 3059-3071

20. Kanpolat Y: The surgical treatment of chronic pain: destructive therapies in the spinal cord. Neurosurg Clin N Am 15:307-317, 2004

21. Kanpolat Y, Akyar S, Cağlar S, Unlü A, Bilgiç S: CT-guided percutaneous selective cordotomy. Acta Neurochir (Wien) 123:92-96, 1993

22. Kanpolat Y, Ozdemir M, Al-Beyati E: CT-guided percutaneous cordotomy for intractable pain in what is more than a disease: lung malignancies. Turk Neurosurg 23:81-87, 2013

23. Kanpolat Y, Savas A, Caglar S, Temiz C, Akyar S: Computerized tomography-guided percutaneous bilateral selective cordotomy. Neurosurg Focus 2(1):e4, 1997

24. Kanpolat Y, Ugur HC, Ayten M, Elhan AH: Computed tomography-guided percutaneous cordotomy for intractable pain in malignancy. Neurosurgery 64 (3 Suppl):ons187ons194, 2009

25. Lukas A, van der Weide M, Boogerd W, Prevoo W, Zuurmond WWA, Sanders M: Adhesive arachnoiditis following percutaneous cervical cordotomy-may we still use lipiodol? J Pain Symptom Manage 36:e1-e4, 2008

26. Mantyh PW: Cancer pain and its impact on diagnosis, survival and quality of life. Nat Rev Neurosci 7:797-809, 2006

27. Meyerson BA: Neurosurgical approaches to pain treatment. Acta Anaesthesiol Scand 45:1108-1113, 2001

28. Mullan S: Percutaneous cordotomy. J Neurosurg 35:360366, 1971

29. Mullan S, Harper PV, Hekmatpanah J, Torres H, Dobbin G: Percutaneous interruption of spinal-pain tracts by means of a strontium ${ }^{90}$ needle. J Neurosurg 20:931-939, 1963

30. Mullan S, Hekmatpanah J, Dobben G, Beckman F: Percutaneous, intramedullary cordotomy utilizing the unipolar anodal electrolytic lesion. J Neurosurg 22:548-553, 1965

31. Nagaro T, Adachi N, Tabo E, Kimura S, Arai T, Dote K: New pain following cordotomy: clinical features, mechanisms, and clinical importance. J Neurosurg 95:425-431, 2001

32. Raslan AM: Percutaneous computed tomography-guided radiofrequency ablation of upper spinal cord pain pathways for cancer-related pain. Neurosurgery 62 (3 Suppl 1):226-234, 2008

33. Raslan AM: Percutaneous computed tomography-guided transdiscal low cervical cordotomy for cancer pain as a method to avoid sleep apnea. Stereotact Funct Neurosurg 83:159-164, 2005

34. Raslan AM, Cetas JS, McCartney S, Burchiel KJ: Destructive procedures for control of cancer pain: the case for cordotomy. J Neurosurg 114:155-170, 2011

35. Rosomoff HL: Bilateral percutaneous cervical radiofrequency cordotomy. J Neurosurg 31:41-46, 1969

36. Rosomoff HL, Brown CJ, Sheptak P: Percutaneous radiofrequency cervical cordotomy: technique. J Neurosurg 23:639_ 644, 1965

37. Rosomoff HL, Papo I, Loeser J: Neurosurgical operations on the spinal cord, in Bonica JJ (ed): The Management of Pain, ed 2. Philadelphia: Lea \& Febiger, 1990, pp 2067-2081

38. Rozet I: Anesthesia for functional neurosurgery: the role of dexmedetomidine. Curr Opin Anaesthesiol 21:537-543, 2008

39. Sarzi-Puttini P, Vellucci R, Zuccaro SM, Cherubino P, Labianca R, Fornasari D: The appropriate treatment of chronic pain. Clin Drug Investig 32 (Suppl 1):21-33, 2012

40. Sindou M, Daher A: Spinal cord ablation procedures for pain, in Dubner R, Gebhart GF, Bond MR (eds): Proceedings of 
the Fifth World Congress on Pain. Amsterdam: Elsevier, 1988, pp 477-495

41. Spiller WG, Martin E: The treatment of persistent pain of organic origin in the lower part of the body by division of the anterolateral column of the spinal cord. JAMA 58:14891490,1912

42. Tasker RR: Percutaneous cordotomy, in Lozano AM, Gildenburg PL, Tasker RR (eds): Textbook of Stereotactic and Functional Neurosurgery. Berlin: Springer, 2009, pp 21372148

43. Tasker RR: Percutaneous cordotomy for persistent pain, in Gildenberg PL, Tasker RR, Franklin PO (eds): Textbook of Stereotactic and Functional Neurosurgery. New York: McGraw-Hill, 1998, pp 1491-1505

44. Tasker RR, Dostrovsky FO: Deafferentation and central pain, in Wall PD, Melzack R (eds): Textbook of Pain. Edinburgh: Churchill-Livingstone, 1989, pp 154-180

45. Teixeira MJ, de Almeida FF, de Oliveira YSA, Fonoff ET: Microendoscopic stereotactic-guided percutaneous radiofrequency trigeminal nucleotractotomy. J Neurosurg 116:331335,2012

46. Willis WD Jr, Coggeshall RE: Sensory Mechanisms of the Spinal Cord: Ascending Sensory Tracts and Their Descending Control. New York: Springer, 2004, Vol 2

\section{Author Contributions}

Conception and design: Fonoff, Teixeira. Acquisition of data: Fonoff, Lopez, de Oliveira. Analysis and interpretation of data: Fonoff, Lopez, de Oliveira. Drafting the article: Fonoff, Lopez. Critically revising the article: Lopez, Teixeira. Reviewed submitted version of manuscript: Fonoff, Lopez, Teixeira. Approved the final version of the manuscript on behalf of all authors: Fonoff. Statistical analysis: Fonoff. Administrative/technical/material support: Teixeira. Study supervision: Teixeira.

\section{Supplemental Information}

\section{Videos}

Video 1, Media Player. http://mfile.akamai.com/21490/wmv/ digitalwbc.download akamai.com/21492/wm.digitalsource-naregional/jns14-1616_video_1.asx.

Video 1, Quicktime. http://mfile.akamai.com/21488/mov/ digitalwbc.download.akamai.com/21492/qt.digitalsource-global/ jns14-1616_video_1.mov.

\section{Correspondence}

Erich Talamoni Fonoff, Rua Dr. Ovídio Pires de Campos, 785 São Paulo 01060-970, Brazil. email: fonoffet@usp.br. 